\begin{tabular}{l|c|c}
\hline \multirow{2}{*}{$\begin{array}{l}\text { EREM 76/3 } \\
\text { Journal of Environmental Research, } \\
\text { Engineering and Management } \\
\begin{array}{l}\text { Vol. 76/ No. 3 / 2020 } \\
\text { pp. 35-46 } \\
\text { Dol 10.5755/j01.erem.76.3.25681 }\end{array}\end{array}$} & \multicolumn{2}{|c}{$\begin{array}{c}\text { Management of Biofuel Production Development on the } \\
\text { Basis of Scenario Planning }\end{array}$} \\
\cline { 2 - 3 } & \multicolumn{2}{|c|}{$\begin{array}{c}\text { Received 2020/03 } \\
\text { Crossef http://dx.doi.org/10.5755/j01.erem.76.3.25681 }\end{array}$} \\
\hline
\end{tabular}

\title{
Management of Biofuel Production Development on the Basis of Scenario Planning
}

\author{
Inna Kuznetsova, Olga Balabash*, Julia Karpenko
}

Odessa National Economic University, Odessa, Ukraine

\section{Oksana Dudziak, Nataliia Semenyshena}

State Agrarian and Engineering University in Podilya, Kamianets-Podilskyi, Ukraine

\author{
Nataliia Semenyshena \\ Ternopil National Economic University, Ternopil, Ukraine
}

\section{*Corresponding author: obalabash@ukr.net}

The aim of the article is to substantiate the methodological approaches of scenario planning in the management of biofuel production development. The following methods were used in order to achieve the goal: cross-factor analysis, scenario planning method, expert methods, and scenario tree. The study analyzed primary energy consumption by economic sector and the total supply of primary energy by source, resulting in a declining supply of non-renewable energy sources such as oil, gas, coal and growing supply of biomass and waste, which was a source of biofuel production. The grouping of biofuel properties from the point of view of its attractiveness as an alternative energy resource was carried out. Factors that can negatively affect the pace of development of biofuel production are systematized. Dominant factors that had a critical impact on the development of biofuels have been identified: fluctuations in prices for electricity production in the traditional way, change in the popularity of greenhouse gas emission reduction programs, fluctuations in the use of electric vehicles, fluctuations in prices for fossil fuels, change in funding for programs to reduce environmental pollution and climate change. Stages of scenario planning with the use of cross-factor analysis were offered. A scenario tree model was formed. A matrix of cross-influence was constructed using expert evaluation and a scale of relations. The procedure of cross-influence and determination of dominant factors influencing the development of the activity "biofuel production" was proposed, which was characterized by the use of cross-factor analysis, which allowed assessing the probability of scenarios, establishing the interaction between them, and further calculating the 
expected effect from the implementation of measures. Applied research results and scenario assessments of the development potential of this area of activity can be used by entrepreneurs in the context of development and further implementation of investment projects for biofuel production.

Keywords: biofuels, alternative energy resources, development factors, scenario planning, cross-factor analysis, cross-impact matrix.

\section{Introduction}

During the twentieth century, the growth of the world economy was facilitated by such a factor as the constant increase in the primary energy production, which by 2030 should be 17,721 million tons, that is 7,698 million tons or 77\% more than in 2000 (International Energy Agency (IEA 2019)).

At the same time, the world demography was experiencing the growth of the middle class at the expense of countries with fast-growing economies. From 1980 to 2010 , the number of the middle class in a world scale increased by 700 million people from 1.1 to 1.8 billion people. With a total population of 7.6 billion people, the increase was $23.74 \%$. According to the UN Population Department (FAO, 2019), the number of the middle class by 2030 will increase by another 500 million people, mainly at the expense of China, where the middle class was 1 billion and 400 million people, and India with 10.7 million people. In the USA and Europe, this indicator was significantly lower, being 365 million and 414 million people in accordance. Nowadays, in China and India, an increase in average income occurs at a rate which is almost ten times higher than the growth during the industrial revolution. Such an increase in the size of the middle class accelerates the corresponding growth in demand for all resources and primarily for energy and fuel.

According to the concept of sustainable development, highlighted in FAO (2019), the activity of humanity should focus not on the growth of consumption of resources of the biosphere, but on its rationalization, eliminating the relationship between economic growth and environmental pollution. These measures were being used to fulfil the obligation for future generations to leave sufficient supplies of social, natural and economic resources.
The rationalization of fossil energy consumption combined with the growing demand for energy determines the need for the development of alternative sources of energy, including biofuels.

The process of biofuel production management required modelling of development options and formation of appropriate strategies. This determines the relevance of scenario planning for this industry.

\section{Methods}

The following methods were used in order to achieve the goal, in particular:

analysis, synthesis and logical-theoretical synthesis for the selection and systematization of the factors of influence;

statistical analysis to study the trend of development of production and export of rapeseed as a raw material for biofuel production;

the method of scenario planning in order to construct scenarios for the possible development of biofuel production;

expert methods to assess the likelihood of impact factors and their development scenarios;

a script tree to form a vector of occurrence probabilities.

\section{Literature review}

Contemporary literature has extensively explored the problems of developing the world grid in the context of the use of renewable energy (Panula-Ontto et al., 2018), providing biofuels (Correa, 2019; Guo et al., 2020), and the features of the biofuel market and delivery platforms (Nugroho and Zhu, 2019). 
Prussi, O'Connell, and Lonza (2019) argued that Europe was a world leader in biofuel technologies (but by 2025 the situation may change) and showed that even if today's EU nominal capacity appears large enough to support the expected aviation biofuels demand, other bottlenecks may limit the real market uptake: availability of sustainable feedstocks, competition with demand for road transport sector, etc.

Javed et al. (2019) made a review of different generations of biofuels. Voca and Ribic (2020) proposed a concrete solution for biofuel consumption and gave an overview of the required land demand for digestate utilization.

In a study by Correa et al. (2019), the environmental impacts of alternative approaches to biofuel production (i.e., first, second, and third generation biofuels), with a focus on biodiversity and ecosystem services, were contrasted to develop a set of criteria for guiding the identification of sustainable biofuel production alternatives (i.e., those that maximize socioeconomic and environmental benefits), as well as strategies for decreasing the economic barriers that prevent the implementation of more sustainable biofuel production systems.

The gradual rise in the cost of mineral resources has revealed a growing interest in the production of biofuels, as an alternative source of energy (Kim et al., 2020; Choi et al., 2020). However, to assess the prospects and investment attractiveness of biofuel production today is difficult, since it is necessary to take into account the influence of multi-directional factors.

Brock, Koder, Rabl, Touraud and Kunz (2020) have developed a new biofuel concept, enabling the usage of vegetable oils and glycerol derivatives in mixtures with biodiesel. Arpia et al. (2020) has reviewed and consolidated the most recent literature regarding the applications of MW-assisted heating for biomass pretreatment as well as biofuel and bioenergy production.

Critical analysis of the scientific literature showed that in most sources scenario planning was used to determine strategic development guidelines (Battistella and Toni, 2011), but the methods, techniques and tools of implementation remain debatable. Most authors have described a number of creative approaches to scripting (Keough and Shanahan, 2008; Kuznetsova, 2019), as well as a variety of expert assessments, including the Delphi method (Ringland, 2002). At the same time, without the authors' attention, there was a need to take into account the cross-influence of environmental factors. In this area, it was in the interest of studying Godet, who proposed the formation of scenarios based on structural analysis and a special diagram of interdependence (Godet, 1993). In our opinion, it was more appropriate to determine the interaction to use cross-factor analysis, which provided an opportunity to formalize the mutual influences of factors (Kenneth, 2008).

Consequently, the task was to determine, on the one hand, the dominant factors and their influence on a definite direction of development, and on the other hand, to establish the cross-factor of the factors among themselves. This task can be solved by using scenario planning tools, which allowed the formation of combinations of factors in order to develop alternative scenarios of development and conduct their evaluation.

The purpose of the article is to establish the cross-sectional impact of the determinants of biofuel production on the definition of dominant among them.

\section{Results and Discussion}

The International Energy Agency has expected a significant increase in energy consumption (FAO, 2019), which by 2030 should be 11,861 million tons, that is by 2,204 million tons or $22.8 \%$ more than in 2015 . At the same time, it is necessary to note the projected growth of biofuel consumption almost 2 times, from 57 million tons to 102 million tons. Total primary energy consumption by sector is presented in Figure 1.

Against the backdrop of reduced supply of non-renewable energy sources such as oil, gas, coal, the supply of biomass and waste, which has been the source for biofuels, tends to increase. The general supply of primary energy by sources is presented in Fig. 2 .

Thus, we see that today that the role of liquid biofuels in the context of total energy consumption has 
Fig. 1. Total primary energy consumption by sectors, $m$ ln tons. Source: summarized by the authors for FAO (2019)

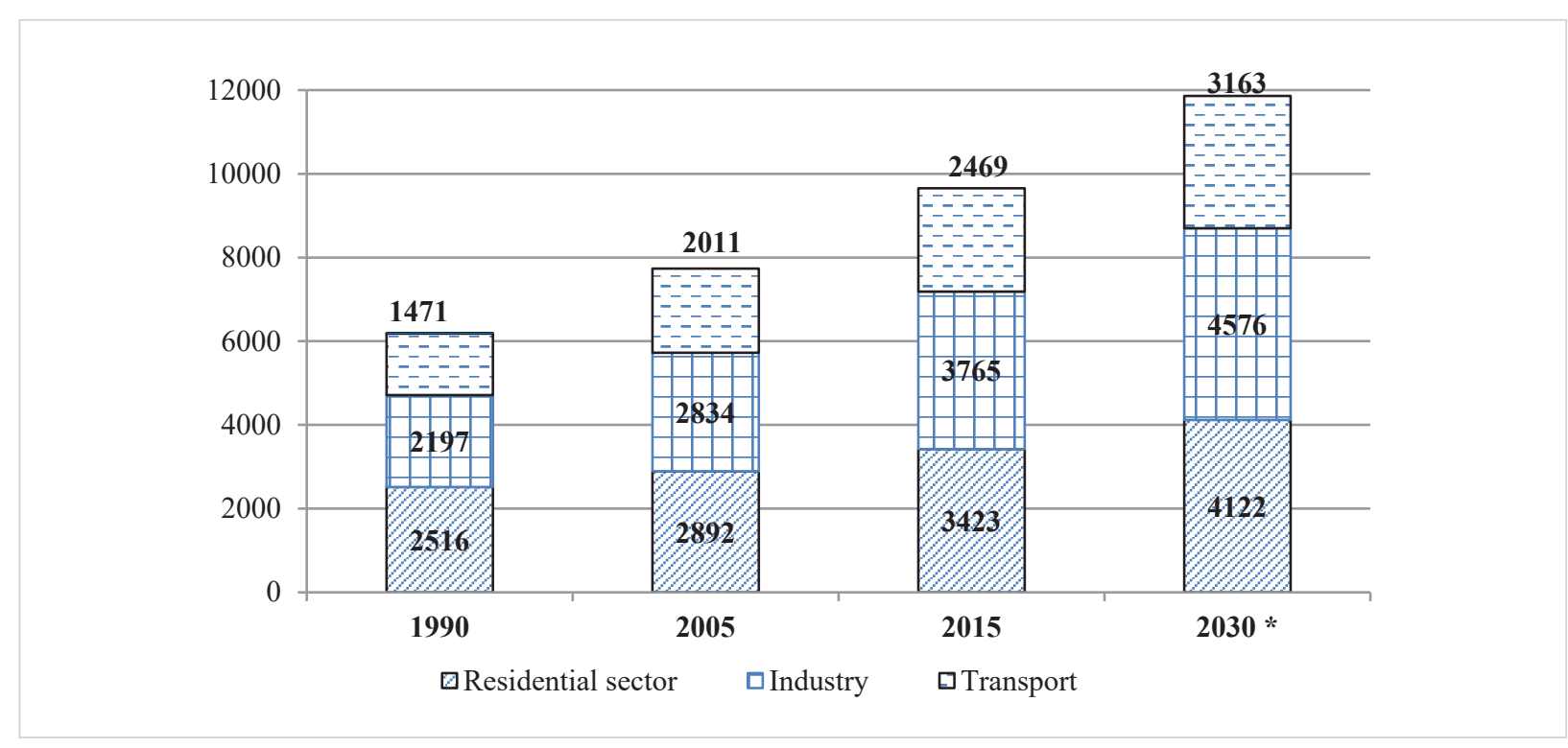

* expected value

Fig. 2. Total supply of primary energy by sources, \%. Source: summarized by the authors for FAO (2019)

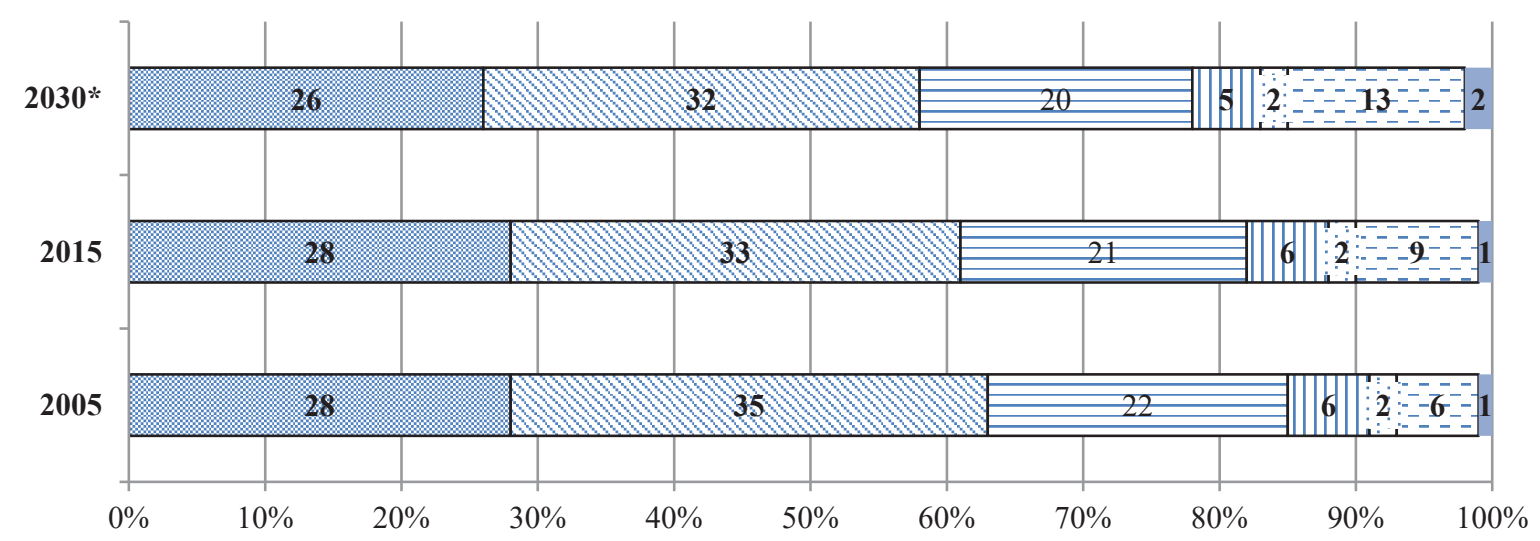

@ Coal $₫$ Oil $\boxminus$ Gas $\square$ Nuclear energy $\square$ Hydropower $\square$ Biomass and waste $\square$ Other renewable sources

been insignificant, but experts predict that over time it will grow. On the other hand, this has been backed up by growing volumes of raw materials for biofuel production. Current world trends are such that fuel consumption is constantly increasing. Therefore, questions about alternative sources have not been relevant. An alternative to biofuels has been quite natural. In addition, biofuels have had a number of properties that are attractive in terms of energy consumption, given as follows:

Reduction of greenhouse gas emissions. Biofuels, especially secondary ones, have played an important role in combating climate change. The global study on greenhouse gas emission reductions in McKinsey's has shown that by 2030 emissions from renewable energy sources will be reduced by 1.4 billion 
tons, which represents $3 \%$ of global emissions in all sectors, or $15 \%$ of emissions in the energy sector.

Reduction of the consumption of non-renewable energy sources. This issue has been of particular relevance in modern conditions, when with increasing prices for fossil fuels, energy production at the expense of traditional technologies has been rising and wholesale prices for electricity have been increasing. As a result, in most European countries, since 2000, energy prices have increased more than twice.

Guarantee of the security of energy supplies. This problem in modern conditions is becoming one of the most important political issues in many countries. Renewable energy can help solve this issue. If $20 \%$ of the electricity consumed in Europe by 2025 is produced using renewable sources, then imports of gas will decrease by 150 billion cubic meters, which is about a quarter of the volume of modern imports.

Today Ukraine has a significant potential for biofuel production.
Firstly, it is connected with the developed raw material base. Thus, each year crops such as rape have been increasing. Rape has been one of the world's leading crops, as a raw material for the production of biofuels, in particular biodiesel.

Ukraine is a leading European rapeseed country. According to the International Grains Council (IGC), in 2019-2020, the GHG is projected to reduce significantly to rapeseed in Europe (up to 5.8 million hectares, the lowest in the last 12 years).

At the same time, Ukraine plans to sow $16 \%$ more space than in the previous period.

It is widely known that rape has been grown in Ukraine for a long period of time, but in recent years its production has grown almost ten times (Figure 3 ).

The negative thing is that raw materials have been exported and the domestic processing of rapeseed has been negligible. Over the last 10 years, almost $90 \%$ of the seeds grown have been exported abroad (Figures 3 and 4).

Fig. 3. Gross collection and export of rapeseed in Ukraine, mln. t.

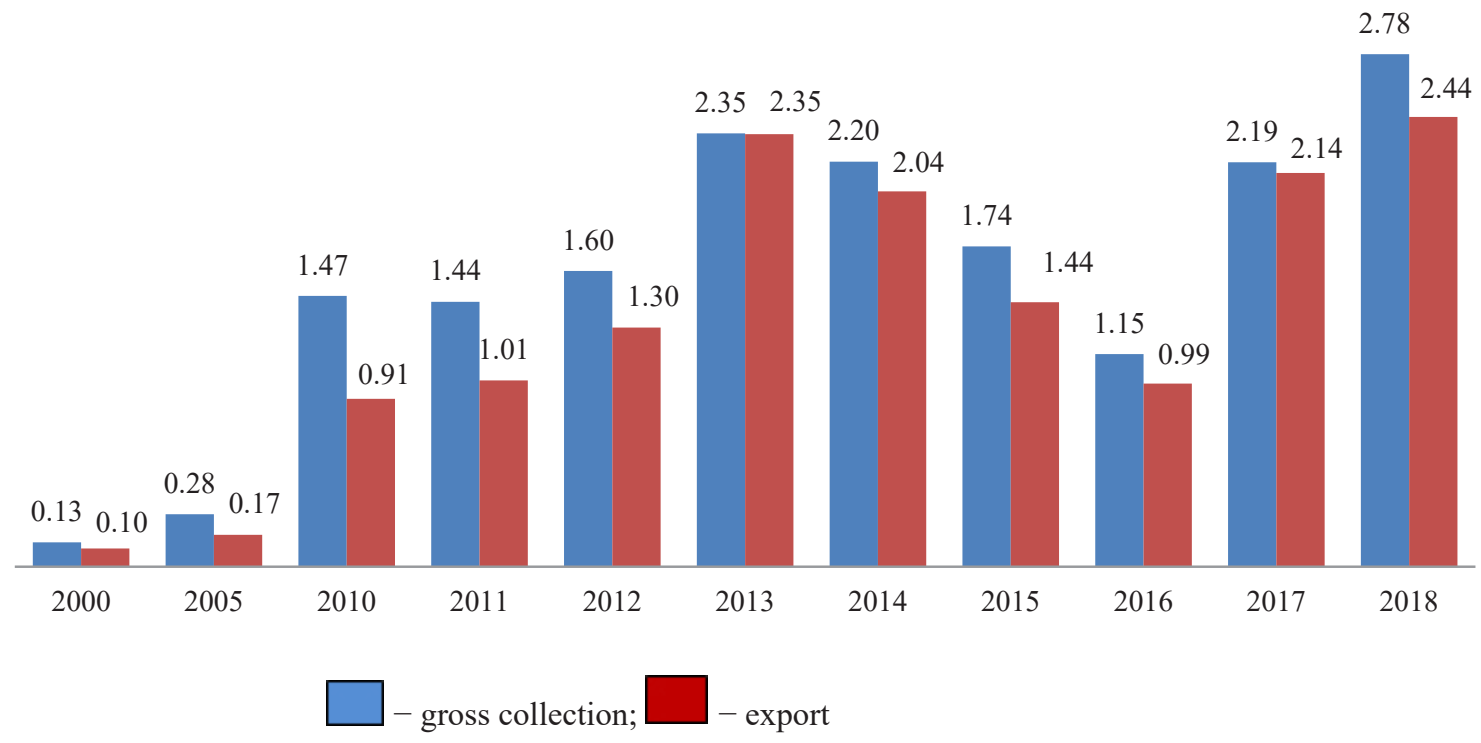

Source: summarized by the authors for Government portal of the State Statistics Committee of Ukraine 
Fig. 4. Rape export share, \%

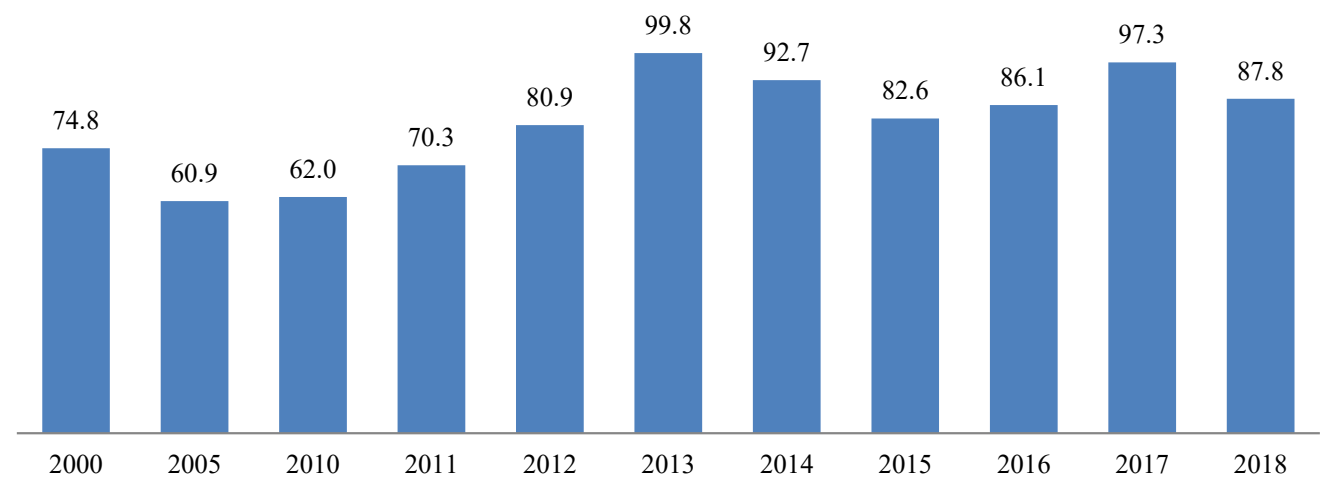

Source: summarized by the authors for Government portal of the State Statistics Committee of Ukraine

We formed a hypothesis based on the above: if there are appropriate conditions, it is economically feasible not only to engage in rapeseed production, but also to focus more on its processing, and in particular, on biofuel processing.

However, the alternative to using biofuels as energy is not straightforward due to a number of negative factors.

It is advisable to use scenario planning based on cross-factor analysis to address this issue. We proposed the following stages of managing the development of biofuel production on the basis of scenario planning based on the study of cross-factor analysis (Kenneth, 2008):

1 systematization of factors of positive and negative influence;

2 building a scenario tree model;

3 construction of matrices of cross-effects of scenarios;

4 calculation of the matrix of cross-exposure;

5 weighing each scenario and assessing the development of biofuel production.

Factors that have a negative impact and can reduce the rate of development of biofuel production include:

1 The risk of a steady fall in prices for fossil fuels. In these conditions, the use of biofuels and other renewable energy sources will not be economically feasible. Along with this, the risk of non-fulfilment of guarantees of energy supplies will decrease.

2 Reducing the profitability of some participants in the production and commercial chain. For exam- ple, an increase in the cost of vegetable oil leads to a decrease in the profitability of biomass power plants.

3 The growth of coal mining and supply can lead to lower prices for coal and electricity, which in turn will negatively affect the attractiveness of biofuels as energy sources.

4 Reducing the relevance of the problem of environmental pollution and climate change can lead to lower support and demand for "green" energy in general and biofuels in particular.

5 Competitiveness of biofuels depends on the political will of the government. In the absence of subsidies from the state, biofuels are generally not competitive, compared with mineral fuels, even at high prices for crude oil. The situation may change the development of technology from its production.

A growing number of developing countries have also been implementing a policy of sustainable development, and in particular promoting the production and consumption of biofuels. Common tools for such policies include the mandatory mixing of biofuels with petroleum fuels, subsidies for biofuel production, tax privileges, and so on. Such a policy has a significant impact on the profitability of biofuel production.

The policy of state support for the production of biofuels negatively affects agricultural markets at the national and world levels, and also has violated the development of an effective international production structure for biofuels and raw materials for its production. 
Prices for biofuels and agricultural raw materials for their production have depended on oil prices, since energy markets have been much larger than agricultural ones.

Energy prices have an impact on prices for agricultural commodities that have a common raw material base, since biofuel raw materials compete with agricultural crops for productive resources.

At the same time, alternative technologies have emerged and are actively developing. For example, electric vehicles. Today, in the world, the segment of electric vehicles is gradually increasing.

According to forecasts, by 2020 electric vehicles will occupy $10 \%$ of the market. In 2017, Ukrainians bought 2,697 passenger electric vehicles, which was 2.3 times more than in 2016. As a result, the share of cars with zero emissions in the primary market of passenger cars was almost $2 \%$. However, the segments of freight, industry and public transport will not be covered soon. There have been also a number of disadvantages that reduced the competitiveness of electric vehicles, compared with conventional ones. This has been a relatively high price, a small stock of stroke and charge duration.

The climate of Ukraine also imposes restrictions on the use of electric vehicles: low temperatures reduce the capacity of batteries and require additional energy costs for heating the car.
Of particular importance are also infrastructure complexities, namely the low branching of the network of charging stations, which, together with long-term charging, impedes the introduction of electric vehicles in Ukraine.

Consequently, on the basis of the foregoing, we can conclude that the process of biofuel production has been associated with a number of factors that need to be systematized, since they have both a positive and a negative impact on the development of this sector.

We will develop scenarios of development in order to verify the possibility and effectiveness of the implementation of biofuels production development. Based on the results of the analysis, we can identify the following critical events for this purpose:

fluctuations in prices for electricity production in the traditional way;

change in the popularity of greenhouse gas emission reduction programs;

fluctuations in the use of electric vehicles;

fluctuations in prices for fossil fuels;

change in funding for programs to reduce environmental pollution and climate change.

We specify possible scenarios of development on the basis of established critical events, based on the method substantiated by Kenneth (2008), (Table 1).

Table 1. Initial data for cross-factor analysis of biofuel production. Source: calculated by the authors

\begin{tabular}{|c|c|c|c|}
\hline Critical situation & Probability of realization & Development scenario & Probability of scenario realization \\
\hline \multirow{3}{*}{$\begin{array}{l}\text { Fluctuations in prices for electricity production } \\
\text { in the traditional way }\end{array}$} & \multirow[t]{3}{*}{0.17} & Decrease (D) & 0.10 \\
\hline & & Constant (C) & 0.15 \\
\hline & & Augmentation $(\mathrm{A})$ & 0.75 \\
\hline \multirow{3}{*}{$\begin{array}{l}\text { Change in the popularity of } \mathrm{GHG} \text { emission } \\
\text { reduction programs }\end{array}$} & \multirow[t]{3}{*}{0.18} & Decrease (D) & 0.10 \\
\hline & & Constant (C) & 0.40 \\
\hline & & Augmentation $(\mathrm{A})$ & 0.50 \\
\hline \multirow[t]{3}{*}{ Fluctuations in the volumes of electric vehicles } & \multirow[t]{3}{*}{0.3} & Decrease (D) & 0.10 \\
\hline & & Constant (C) & 0.35 \\
\hline & & Augmentation (A) & 0.55 \\
\hline \multirow[t]{3}{*}{ Fluctuations in prices for fossil fuels } & \multirow[t]{3}{*}{0.2} & Decrease (D) & 0.35 \\
\hline & & Constant (C) & 0.20 \\
\hline & & Augmentation $(\mathrm{A})$ & 0.45 \\
\hline \multirow{3}{*}{$\begin{array}{l}\text { Changes in funding for programs to reduce } \\
\text { environmental pollution and climate change }\end{array}$} & \multirow[t]{3}{*}{0.15} & Decrease (D) & 0.33 \\
\hline & & Constant (C) & 0.33 \\
\hline & & Augmentation (A) & 0.34 \\
\hline Amount of probability & 1 & & \\
\hline
\end{tabular}


Fig. 5. Model of a scenario tree of biofuel production development

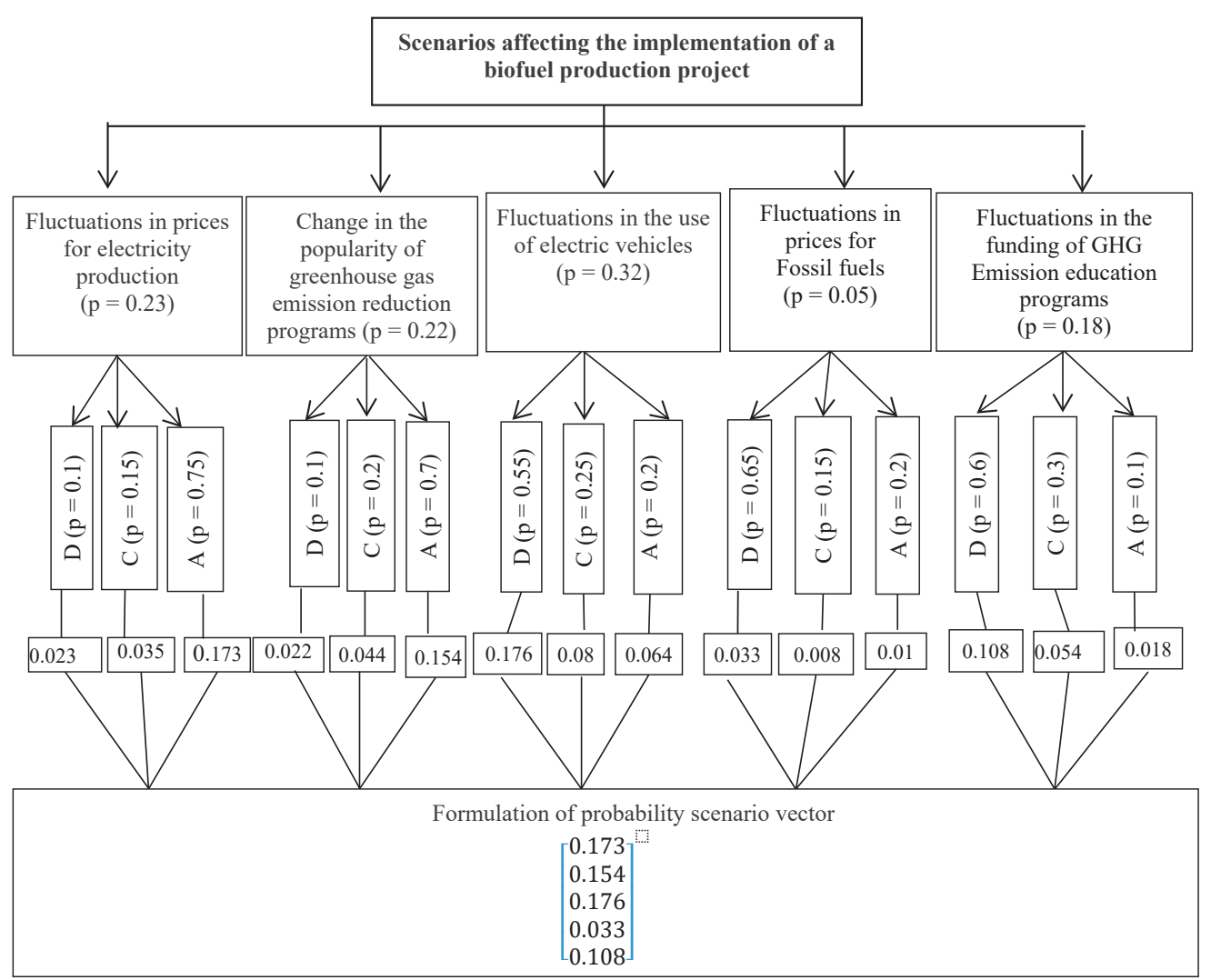

Source: calculated by the authors

The expert method will determine the probability of occurrence of events and determine the probability of the onset of scenarios (Table 1).

In order to visualize the development of events and the probability of their occurrence, as well as calculation of the probability of each scenario, we will construct a scenario tree (Figure 5).

Therefore, we identified a number of factors affecting the production of biofuels and generated certain development scenarios. Their specificity was mutual cross-influence. For example, promoting greenhouse gas emission reduction programs will reduce the negative impact of increasing use of electric vehicles.

Therefore, the question arose to take into account this crossover influence and to determine the dominant factors. For this purpose, it was appropriate to conduct a cross-factor analysis.
Most likely, taking into account the cross-impact of factors will allow the formation of two matrices (Kenneth, 2008), which would take into account on the one hand the influence of one factor on the other, and on the other hand, their chain influence.

To establish mutual influences of the chosen scenarios, we constructed a matrix of cross-influences (Table 2). It allows establishing the interaction of selected events. The matrix of cross-impacts allowed presenting the impact of one scenario taking into account the onset of another on the implementation of measures for the development of biofuel production. Expert methods and a scale of relations from -5 to +5 are used to determine the degree and direction of influence.

To reflect the probability of the impact of some scenarios, provided that they have already occurred, on others, a matrix of conditional probabilities of cross-influences was constructed (Table 3). 
Table 2. The cross-impact matrix of scenarios for the development of biofuel production

\begin{tabular}{|c|c|c|c|c|}
\hline \multirow[b]{2}{*}{$\begin{array}{l}\text { Mutual influence of scenarios } \\
\text { The increase in the production of electricity in the traditional way }\end{array}$} & \multicolumn{4}{|c|}{ Leading events } \\
\hline & 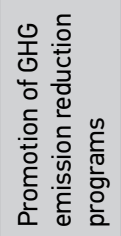 & 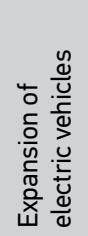 & 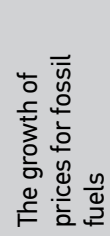 & 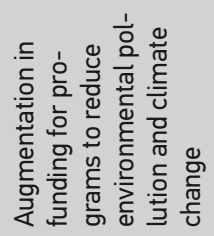 \\
\hline
\end{tabular}

\section{Managed events}

\begin{tabular}{l|l|l|l|l}
\hline The increase in the production of electricity in the traditional way & 3 & 2 & 2 & 1 \\
\hline Promotion of GHG emission reduction programs & 1 & 2 & 4 & 2 \\
\hline $\begin{array}{l}\text { Expansion of electric vehicles } \\
\text { The growth of prices for fossil fuels }\end{array}$ & 1 & 3 & -4 & 1 \\
\hline $\begin{array}{l}\text { Augmentation in funding for programs to reduce environmental pollution } \\
\text { and climate change }\end{array}$ & 3 & 5 & 2 & 3 \\
\hline
\end{tabular}

Source: calculated by the authors

Table 3. The matrix of conditional probabilities of cross-impact scenarios for the development of biofuel production

\begin{tabular}{|c|c|c|c|c|c|}
\hline \multirow[b]{2}{*}{$\begin{array}{l}\text { Mutual influence of scenarios } \\
\text { The increase in the production of electricity in } \\
\text { the traditional way }\end{array}$} & \multicolumn{5}{|c|}{ Leading events } \\
\hline & 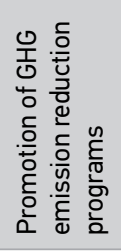 & 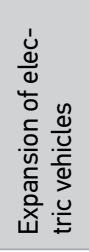 & 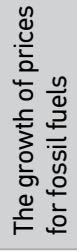 & 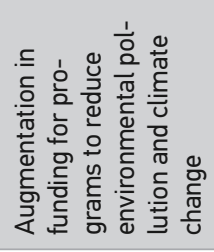 & \\
\hline \multicolumn{6}{|c|}{ Managed events } \\
\hline The increase in the production of electricity in the traditional way & 1 & 0 & 0 & 0 & 0 \\
\hline Promotion of GHG emission reduction programs & 0.1 & 1 & 0 & 0.8 & 0.1 \\
\hline Expansion of electric vehicles & 0.1 & 0.7 & 1 & 0.5 & 0.3 \\
\hline The growth of prices for fossil fuels & 0 & 0 & 0 & 1 & 0 \\
\hline $\begin{array}{l}\text { Augmentation in funding for programs to reduce environmental } \\
\text { pollution and climate change }\end{array}$ & 0 & 0 & 0.1 & 0.7 & 1 \\
\hline
\end{tabular}

Source: calculated by the authors

The cross-impact matrix allows demonstrating the impact of one scenario, taking into account the onset of another on the implementation of measures to develop biofuel production.

The scale from -5 to +5 can be used in order to determine the degree and direction of influence.

A matrix of conditional probabilities of cross-effects was constructed (Table 3).

We formed two cross-factor matrices based on the assessment of factor impacts: matrix $A$ was a matrix of cross-impacts of scenarios, and matrix B was a matrix of conditional probabilities of cross-impacts of scenarios for the development of biofuel production.

$A=\left[\begin{array}{rrrrr}3 & 2 & 2 & 1 & 2 \\ 1 & 2 & 4 & 2 & 3 \\ 1 & 3 & -4 & 1 & 2 \\ 1 & 3 & 2 & 3 & 3 \\ 3 & 5 & 2 & 3 & 3\end{array}\right]$ 


$$
B=\left[\begin{array}{ccccc}
1 & 0 & 0 & 0 & 0 \\
0.1 & 1 & 0 & 0.8 & 0.1 \\
0.1 & 0.7 & 1 & 0.5 & 0.3 \\
0 & 0 & 0 & 1 & 0 \\
0 & 0 & 0.1 & 0.7 & 1
\end{array}\right]
$$

The cross-exposure matrix $(X)$ was obtained as the product of matrix $A$ and matrix $B$.

$$
\begin{aligned}
X & =\left[\begin{array}{rrrrr}
3 & 2 & 2 & 1 & 2 \\
1 & 2 & 4 & 2 & 3 \\
1 & 3 & -4 & 1 & 2 \\
1 & 3 & 2 & 3 & 3 \\
3 & 5 & 2 & 3 & 3
\end{array}\right] \times\left[\begin{array}{ccccc}
1 & 0 & 0 & 0 & 0 \\
0.1 & 1 & 0 & 0.8 & 0.1 \\
0.1 & 0.7 & 1 & 0.5 & 0.3 \\
0 & 0 & 0 & 1 & 0 \\
0 & 0 & 0.1 & 0.7 & 1
\end{array}\right]= \\
& =\left[\begin{array}{rrrrr}
3.4 & 3.4 & 2.2 & 5 & 2.8 \\
1.6 & 4.8 & 4.3 & 7.7 & 4.4 \\
0.9 & 0.2 & -3.8 & 2.8 & 1.1 \\
1.5 & 4.4 & 2.3 & 8.5 & 3.9 \\
3.7 & 6.4 & 2.3 & 10.1 & 4.1
\end{array}\right]
\end{aligned}
$$

Estimation of the chosen direction of development will be held by weighing each scenario and calculating the vector $\mathrm{S}$ :

$\mathrm{S}=\left[\begin{array}{ccccc}3.4 & 3.4 & 2.2 & 5 & 2.8 \\ 1.6 & 4.8 & 4.3 & 7.7 & 4.4 \\ 0.9 & 0.2 & -3.8 & 2.8 & 1.1 \\ 1.5 & 4.4 & 2.3 & 8.5 & 3.9 \\ 3.7 & 6.4 & 2.3 & 10.1 & 4.1\end{array}\right] \times\left[\begin{array}{l}0.173 \\ 0.154 \\ 0.176 \\ 0.033 \\ 0.108\end{array}\right]=\left[\begin{array}{c}1.9664 \\ 2.5021 \\ -0.2711 \\ 2.0436 \\ 2.8066\end{array}\right](4)$

By adding all the elements of the vector, we got a number equal to 9.0476 , indicating a positive cross-impact of factors. Thus, according to the results of cross-factor analysis, it should be noted that we specified a number of scenarios, the implementation of which will have a negative impact on the development of biofuel production in Ukraine, namely: a decrease of prices for electricity production in the traditional way, loss of popularity of programs for reducing greenhouse gas emissions, a decrease of prices for fossil fuels, growth of volumes of use of electric vehicles, a decrease of funding programs for reducing environmental pollution and climate change.

The results of the analysis showed that most of them have low probability of occurrence. The factor Increase in the use of electric vehicles has a high probability of onset and may have a negative impact on the development of biofuel production.

\section{Conclusions}

According to the analysis, it was thoroughly proved that the role of liquid biofuels in the context of aggregate energy consumption would increase. The expediency of intensification of biofuel production was substantiated.

The dominant factors that have a significant impact on the development of this area are specified and investigated: fluctuations in prices for electricity production in the traditional way, change in the popularity of greenhouse gas emission reduction programs, fluctuations in the use of electric vehicles, fluctuations in prices for fossil fuels, change in funding for programs to reduce environmental pollution and climate change.

The selected factors have both negative and positive impact on the development of biofuel production. Factors also affect each other. Thus, popularization of programs to reduce greenhouse gas emissions will help reduce the negative impact of the spread of the use of electric vehicles. In this regard, it becomes important to take into account the mutual influence of selected factors.

Using the method of cross-factor analysis, the cross-sectional influence of the factors of development of biofuel production was investigated and the dominant factors were determined. The advantages of cross-factor analysis in practical application in the process of managing the development of biofuel production were proved.

Thus, it was proved that the production of biofuels was appropriate provided that the change in the use of electric vehicles was monitored.

\section{Acknowledgments}

This research did not receive any specific grant from funding agencies in the public, commercial, or notfor-prof it sectors. 


\section{References}

Arjay A. Arpia, A.A., Chen, W-Y., Lam, Su Shiung, Rousset, P., De Luna, V.D. (2020) Sustainable biofuel and bioenergy production from biomass waste residues using microwave-assisted heating: A comprehensive review. Chemical Engineering Journal, 126233. https://doi.org/10.1016/j.cej.2020.126233

Battistella, C. and Toni, A. (2011) A methodology of technological foresight: A proposal and field study. Technological Forecasting and Social Change,78, 1029-1048. https://doi.org/10.1016/j. techfore.2011.01.006

Brock, D., Koder, A., Rabl, H-P., Touraud, D., Kunz, W. (2020) Optimising the biodiesel production process: Implementation of glycerol derivatives into biofuel formulations and their potential to form hydrofuels. Fuel, 264, 116695. https://doi. org/10.1016/j.fuel.2019.116695

Chen, J., Li, C., Ristovski, Z., Milic, A., Gu, Y., Islam, M.S., Wang, S., Hao, J., ... Dumka, U.C. (2017) A review of biomassburning: emissions and impactsonair quality, health and climate in China. Sci. TotalEnviron, 579, 1000-1034. https://doi.org/10.1016/j. scitotenv.2016.11.025

Choi, K. R., Jiao, S., \& Lee, S. Y. (2020) Metabolic Engineering Strategies toward production of biofuels. Current Opinion in Chemical Biology, 59, 1-14. https://doi.org/10.1016/j. cbpa.2020.02.009

Correa, D., Beyer, H., Fargione, J., Hill, J., Possingham, H., Thomas-Hall, S., Schenk, P. (2019) Towards the implementation of sustainable biofuel production systems. Renewable and Sustainable Energy Reviews, 107, 250-263. https://doi. org/10.1016/j.rser.2019.03.005

Correa, D.F., Beyer, H.L., Fargione, J.E., Hill, J.D., Possingham, H.P., Thomas-Hall, S.R., Schenk, P.M. (2019) Towards the implementation of sustainable biofuel production systems. Renewable and Sustainable Energy Reviews, 107, 250-263. https:// doi.org/10.1016/j.rser.2019.03.005

Ventura, M., Lima, S.M., Andrade, L. L., Simionatto, E. \& Figueiredo, M. (2014) Identification of adulterant and alcohol route in biodiesel using mid-infrared absorption spectroscopy. Independent Journal of Management \& Production, 5(1), 264-274. https://doi.org/10.14807/ijmp.v5i1.136

Da Silva, T.A.R., Santos, D.Q., Neto, W.B. \& De Lima, A.P. (2013) Model for the correction of the specific gravity of biodiesel from residual oil. Independent Journal of Management \& Production, 4(1), 136-147. DOI: 10.14807/ijmp.v4i1.65. https://doi. org/10.14807/ijmp.v4i1.65

Esteves, R.A. \& Pereira, R. G. ( 2017) Comparing the environmental impacts of ethyl biodiesel production from soybean oil and beef tallow through Ica for brazilian conditions. Independent Journal of Management \& Production, 8(4), 1285-1304. https://doi.org/10.14807/ijmp.v8i4.644

IEA (2019) Data and statistics. https://www.iea.org/data-and-statistics?country=WORLD\&fuel=Energy $\% 20$ supply\&indicator=Total\%20primary $\% 20$ energy $\% 20$ supply $\% 20$ (TPES)\%20by\%20source

FAO (2019) Ensure sustainable consumption and production patterns. Sustainable Development Goals. Retrievied fromhttp://www.fao.org/sustainable-development-goals/goals/ goal-12/en/

FAO (2019) How to feed the world's population in 2050. Retrievied fromhttp://www.fao.org/fileadmin/templates/wsfs/docs/ synthesis_papers/How_to_Feed_the_World_in_2050_RU.pdf

Governmentportal of the State Statistics Committee of Ukraine http://ukrstat.gov.ua

Gumbytè, M., Makareviciene, V. \& Sendžikienè E. (2011) Esterification of By-products of Biodiesel Fuel Production with Methanol and Technical Glycerol Using Biocatalysts. Environmental Research, Engineering and Management, 56(2), 28-34. https:// doi.org/10.5755/j01.erem.56.2.334

Guo, Q., Cheng, Z., Chen, G., Yan, B., Hou, L., \& Ronsse, F. (2020). Optimal strategy for clean and efficient biomass combustion based on ash deposition tendency and kinetic analysis. Journal of Cleaner Production, 271. https://doi.org/10.1016/j.jclepro.2020.122529

Ivanyshyn, V., Nedilska, U. ...: Dziedzic, K. (2018) Prospects of Growing Miscanthus as Alternative Source of Biofuel. In: Renewable Energy Sources: Engineering, Technology, Innovation: ICORES 2017, 801-812. https://doi.org/10.1007/978-3-31972371-6_78

Javed, M.R., Noman, M., Shahid, M., Ahmed, T., Khurshid, M., Rashid, M.H., Ismail, M. ... Fahad Khan (2019) Current situation of biofuel production and its enhancement by CRISPR/ Cas9-mediated genome engineering of microbial cells. Microbiological Research, 219, 1-11. https://doi.org/10.1016/j.micres.2018.10.010

Kazanceva, I., Makareviciene, V. \& Kazancev K. (2011) Application of Biotechnological Method to Biodiesel Fuel Production using n-butanol. Environmental Research, Engineering and Management, 2(56), 35-42. https://doi.org/10.5755/j01. erem.56.2.376

Kenneth, Ch. (2008) A New Look at the Cross-Impact Matrix and its Application in Futures Studies. Journal of Futures Studies. 12(4). 45-52. 
Keough, S. M., \& Shanahan, K. J. (2008) Scenario planning: Toward a more complete model for practice. Advances in Developing Human Resources, 10(2), 166-178. https://doi. org/10.1177/1523422307313311

Kim, Y., Thomas, A. E., Robichaud, D. J., lisa, K., St. John, P. C., Etz, B. D., ... Kim, S. (2020) A perspective on biomass-derived biofuels: From catalyst design principles to fuel properties. Journal of Hazardous Materials, 400. https://doi.org/10.1016/j.jhazmat.2020.123198

Makarevičienè V., Andrulevičiūtè, V., Skorupskaitè, V. \& Kasperovičienè, J (2011) Cultivation of Microalgae Chlorella sp. and Scenedesmus sp. as a Potentional Biofuel Feedstock. Environmental Research, Engineering and Management, 3(57), 21-27.

Nugroho, Y.,\&Zhu, L. (2019) Platforms planning and process optimization for biofuels supply chain. Renewable Energy, 140, 563-579. https://doi.org/10.1016/j.renene.2019.03.072
Panula-Ontto, J., Luukkanen, J., Kaivooja, J., O'Mahony, T., Vehmas, J., Valkealahti, S., Björkqvist, T., ... Repo, S. (2018) Cross-impact analysis of Finnish electricity system with increased renewables: Long-run energy policy challenges in balancing supply and consumption. Energy Policy, 118, 504-513. https://doi.org/10.1016/j.enpol.2018.04.009

Prussi, M., O'Connell, A. \& Lonza, L. (2019) Analysis of current aviation biofuel technical production potential in EU28. Biomass and Bioenergy, 130, 105371. https://doi.org/10.1016/j.biombioe.2019.105371

Voca, N., Ribic, B. (2020) Biofuel production and utilization through smart and sustainable biowaste management. Journal of Cleaner Production, 259, 2020, 120742. https://doi. org/10.1016/j.jclepro.2020.120742 